\section{O programa de controle da esquistossomose em dois municípios da zona da mata de Pernambuco: uma análise de implantação}

Louisiana Regadas de Macedo Quinino 1 Constança Simões Barbosa 2 Isabella Samico 3

1,2 Centro de Pesquisas Aggeu Magalhães (CPqAM/Fiocruz). Av. Prof Moraes Rêgo. Cidade Universitária. Recife, PE, Brasil. CEP: 50.670-420. E-mail: louisianaquinino@cpqam.fiocruz.br 3 Instituto de Medicina Integral Prof. Fernando Figueira (IMIP). Recife, PE, Brasil.

\begin{abstract}
Objectives: to understand the factors that give rise to variations in the degree of implementation (DI) of the Schistosomiasis Control Program (SCP) in two municipalities in the Brazilian State of Pernambuco.

Methods: an implementation analysis was undertaken to evaluate the influence of the context the DI of the SCP. Structured questionnaires were used to interview SCP coordinators, health secretaries, and environmental health coordinators and agents. Research was also carried out using official records and direct observation. A points system was used to classify the DI of the SCP as implemented (90 to 100 points), partially implemented ( 60 to 89 points) and not implemented $(<59)$.

Results: the DI of the SCP in the first municipality was "not implemented" (52.85 points) and in the second municipality 'partially implemented' (63.65 points). The main impediments to the implementation of schistosomiasis control measures were lack of knowledge of how the SCP works, insufficient planning of control measures, low priority given to the program, insufficient infrastructure, and failure to include control measures in tools used to manage and centralize action.

Conclusions: there is a need to rethink the way schistosomiasis is controlled and to contemplate integrated and equitable decentralization of action, with a view to moving beyond the existing paradigm.
\end{abstract}

Key words Schistosomiasis mansoni, Program evaluation, Health policy

\section{Resumo}

Objetivos: conhecer os fatores intervenientes na variação do grau de implantação (GI) do Programa de Controle da Esquistossomose (PCE) em dois municípios de Pernambuco.

Métodos: análise de implantação, que avaliou a influência do contexto no GI do PCE. Utilizaram-se questionários estruturados que foram aplicados aos coordenadores do PCE, aos secretários de saúde, coordenadores e agentes de saúde ambiental. Também foram pesquisados registros oficiais e realizou-se observação direta. Empregou-se um sistema de escores que classificou o GI do PCE em implantado (90 a 100 pontos), parcialmente implantado (60 a 89 pontos) e não implantado $(<59)$.

Resultados: GI do PCE no município 1 foi 'não implantado' (52,85 pontos) e no municipio 2 foi 'parcialmente implantado' (63,65 pontos). Os principais empecilhos para a implantação das ações de controle da esquistossomose foram pouco conhecimento sobre o funcionamento do PCE, planejamento precário das ações de controle, pouca prioridade dada ao programa, e estrutura insuficiente, não contemplação de ações de controle em instrumentos de gestão e centralização de ações.

Conclusões: há necessidade de repensar o controle da esquistossomose considerando a descentralização das ações sob a perspectiva da integralidade e equidade, visando superar paradigmas.

Palavras-chave Esquistossomose mansoni, Avaliação de programas, Política de saúde 


\section{Introdução}

Pernambuco é um dos Estados brasileiros que exibem percentuais médios mais elevados de pessoas com esquistossomose, 1 sendo a zona da mata a região mais atingida, apresentando áreas com até $80 \%$ de indivíduos parasitados. ${ }^{2}$ Inquérito recente detectou uma prevalência média de $14,4 \%$ para esse Estado. ${ }^{3}$ Desde a década de 1990 tem-se observado a expansão da esquistossomose para áreas litorâneas e Região Metropolitana do Recife (RMR), com casos agudos da doença registrados na Praia de Itamaracá, 4-6 na Praia de Porto de Galinhas7 e em várias outras localidades litorâneas do Estado.

A oficialização do controle da esquistossomose foi efetivada em 1975 com a criação do Programa Especial de Controle da Esquistossomose (PECE), pela Superintendência de Campanhas de Saúde Pública (SUCAM), sendo substituído pelo Programa de Controle da Esquistossomose (PCE) na década seguinte. 8,9 Em 1999 foi normatizada a descentralização da execução das ações de epidemiologia e controle de doenças, entre elas, a esquistossomose, que saem da gestão da Fundação Nacional de Saúde (FUNASA), originada, em 1990, pela fusão entre a Fundação Serviços Especiais de Saúde Pública (Fundação SESP) e a SUCAM, passando a ser da competência dos municípios. 10

Objetivando a realização das atividades de controle da esquistossomose de forma correta pelas instâncias municipais, o Ministério da Saúde (MS) recomenda as seguintes ações: delimitação epidemiológica, inquéritos coproscópicos censitários, tratamento de infectados, controle de moluscos, saneamento ambiental, educação em saúde, vigilância epidemiológica e a alimentação do sistema de informação do PCE (SISPCE). Todas essas atividades devem ser incorporadas àquelas desenvolvidas pelo Programa de Agentes Comunitários de Saúde (PACS) e Programa de Saúde da Família (PSF).11,12

Em Pernambuco, a descentralização das ações de controle da esquistossomose ocorreu no período entre 1999 e 2000 . A forma como estão sendo realizadas estas atividades após a municipalização, no entanto, tem apresentado problemas. Trabalhos realizados por Farias et al.13 e Quinino et al. ${ }^{14}$ mostram várias dificuldades enfrentadas pelos municípios na operacionalização das ações de controle da esquistossomose, que incluem a realização de atividades de controle de forma não integral e desarticulada.

Nesse sentido, considerando-se a magnitude da esquistossomose como um problema de saúde pública em Pernambuco e a carência de estudos avaliativos que abordem as ações de controle da esquistossomose, este estudo teve como objetivo avaliar a implantação do PCE em dois municípios da zona da mata de Pernambuco, identificando o nível de cumprimento das normas e critérios preconizados pelo programa (grau de implantação) e os determinantes contextuais implicados na implantação desse programa.

\section{Métodos}

Pesquisa avaliativa, tipo análise de implantação em seu primeiro componente, que se caracteriza pela análise da influência dos determinantes contextuais no grau de implantação das intervenções. ${ }^{15}$

Os municípios que fizeram parte do estudo enquadraram-se nos seguintes critérios: a) pertencer à zona da mata Pernambucana; b) ser habilitado para as ações de endemias; c) não ter mudado de gestão na última eleição; d) ter a maior população; e) ter realizado o maior número de exames coproscópicos desde a implantação do PCE. Com esses critérios, foram identificados dois municípios, aqui denominados 1 e 2 .

O estudo foi realizado em três etapas, sendo que a primeira correspondeu à construção do modelo lógico do PCE, que seguiu os quatro estágios propostos por McLaughlin e Jordan, 16 com ênfase na coleta de informações a partir de várias fontes.11,12,17-19 Este exercício permitiu a construção de um modelo adaptado à proposta atual de controle da esquistossomose de acordo com o Sistema Único de Saúde (SUS), apesar de o mesmo não ter sido submetido a técnicas de consenso. O modelo utilizado no estudo pode ser visto em artigo publicado por Quinino et al.20

A segunda etapa consistiu no cálculo do grau de implantação (GI) e, a terceira, na análise dos determinantes contextuais do grau de implantação do PCE. Para a avaliação do GI foi empregado um questionário estruturado, elaborado a partir do modelo lógico, aplicado aos coordenadores do PCE nos municípios do estudo por meio de entrevista dirigida e observação sistemática (dados primários). Para complementação dos dados foi agregada uma análise do sistema de informações sobre o Programa de Controle da Esquistossomose (SISPCE) municipal (dados secundários).

Para análise do contexto utilizaram-se formulários estruturados, aplicados aos coordenadores do PCE, aos agentes de saúde ambiental (ASA) e aos secretários de saúde, bem como observação sistemática e análise dos planos municipais de saúde.

Para estabelecer o grau de implantação do PCE, 
utilizou-se um sistema de escores, no qual cada subcomponente das dimensões estrutura (Tabela 1) e processo (Tabela 2) recebeu pontuação de acordo com a importância do item para o controle da esquistossomose. Às variáveis dicotômicas da estrutura e do processo foram atribuídos pontos, de modo que o somatório foi de 80 , para cada dimensão. Para os indicadores de habilitação profissional (estrutura), estabeleceram-se pontos de acordo com o seguinte indicador: profissionais de uma determinada categoria treinados em sua função específica/total de profissionais desta mesma categoria existentes $\mathrm{X}$
100. Este processo adotou os seguintes pontos de corte: de 80 a $100 \%$ de profissionais treinados $=2$ pontos; de 50 a $79 \%=1$ ponto; menos de $50 \%=0$ ponto (total 20 pontos). Para os indicadores de cobertura (processo), a cada faixa de percentual atingida por indicador foi atribuída uma pontuação com os pontos de corte: de 80 a $100 \%=5$ pontos; de 50 a $79 \%=2,5$ pontos e menos de $49 \%=0$ ponto (total 20 pontos). O total geral possível de ser atingido por cada dimensão, portanto, foi de 100 pontos.

Tabela 1

Distribuição da pontuação atingida por subcomponente e pontuação total da dimensão estrutura nos municípios 1 e 2 . Pernambuco, 2009.

\begin{tabular}{|c|c|c|c|c|}
\hline Componente & Subcomponente & $\begin{array}{l}\text { Pontuação } \\
\text { máxima }\end{array}$ & $\begin{array}{c}\text { Pontuação atingida/ } \\
\text { município } 1\end{array}$ & $\begin{array}{c}\text { Pontuação atingida/ } \\
\text { município } 2\end{array}$ \\
\hline \multirow{16}{*}{$\begin{array}{l}\text { Recursos } \\
\text { materiais }\end{array}$} & Potes & 2,0 & 1,0 & 0,0 \\
\hline & Etiquetas marcadoras & 2,0 & 0,0 & 0,0 \\
\hline & Formulário PCE 101 & 2,0 & 2,0 & 2,0 \\
\hline & Veículo & 2,0 & 1,0 & 2,0 \\
\hline & Mapa & 2,0 & 0,0 & 0,0 \\
\hline & Croqui & 2,0 & 0,0 & 0,0 \\
\hline & Laboratório Municipal & 5,0 & 5,0 & 5,0 \\
\hline & Material de laboratório & 14,0 & 8,0 & 10,0 \\
\hline & Praziquantel & 2,0 & 0,0 & 0,0 \\
\hline & Material Malacologia & 6,0 & 0,0 & 0,0 \\
\hline & Computador & 2,0 & 2,0 & 2,0 \\
\hline & $\begin{array}{l}\text { NESMS implantado/ } \\
\text { profissional treinado }\end{array}$ & 2,0 & 0,0 & 0,0 \\
\hline & Material educativo & 2,0 & 2,0 & 2,0 \\
\hline & Coordenador do PCE & 5,0 & 5,0 & 5,0 \\
\hline & Agente de Saúde Ambiental & 5,0 & 5,0 & 5,0 \\
\hline & Motorista & 5,0 & 2,5 & 5,0 \\
\hline \multirow{7}{*}{$\begin{array}{l}\text { Recursos } \\
\text { humanos }\end{array}$} & Técnico de laboratório & 5,0 & 5,0 & 5,0 \\
\hline & Auxiliar de laboratório & 5,0 & 0,0 & 5,0 \\
\hline & $\begin{array}{l}\text { Núcleo de Educação em Saúde } \\
\text { e Mobilização Social }\end{array}$ & 5,0 & 0,0 & 0,0 \\
\hline & Digitador & 5,0 & 5,0 & 5,0 \\
\hline & ASA & 2,0 & 2,0 & 0,0 \\
\hline & Médicos & 2,0 & 0,0 & 0,0 \\
\hline & Enfermeiros & 2,0 & 0,0 & 0,0 \\
\hline \multirow{7}{*}{$\begin{array}{l}\text { Indicadores de } \\
\text { cobertura de } \\
\text { habilitação } \\
\text { profissional }\end{array}$} & ACS & 2,0 & 0,0 & 0,0 \\
\hline & Coord. endemias/PCE & 2,0 & 2,0 & 0,0 \\
\hline & Gerente vigilância & 2,0 & 0,0 & 2,0 \\
\hline & Laboratorista & 2,0 & 2,0 & 2,0 \\
\hline & Aux. laboratório & 2,0 & 0,0 & 0,0 \\
\hline & Educadores & 2,0 & 0,0 & 0,0 \\
\hline & Digitadores & 2,0 & 2,0 & 0,0 \\
\hline Total de pontos & & 100,0 & 51,5 & 62,0 \\
\hline
\end{tabular}

PCE $=$ Programa de Controle da Esquistossomose; $A S A=$ agentes de saúde ambiental; $\mathrm{ACS}=$ Agentes Comunitários de Saúde; NESMS=Núcleo de Educação em Saúde e Mobilização Social. 
Tabela 2

Distribuição da pontuação atingida por subcomponente e pontuação total da dimensão processo nos municípios 1 e 2 . Pernambuco, 2009.

\begin{tabular}{|c|c|c|c|c|}
\hline Componente & Subcomponente & $\begin{array}{l}\text { Pontuação } \\
\text { máxima }\end{array}$ & $\begin{array}{l}\text { Pontuação atingida/ } \\
\text { município } 1\end{array}$ & $\begin{array}{c}\text { Pontuação atingida/ } \\
\text { município } 2\end{array}$ \\
\hline \multirow[t]{5}{*}{$\begin{array}{l}\text { Delimitação } \\
\text { epidemiológica }\end{array}$} & $\begin{array}{l}\text { Realização de inquérito } \\
\text { coproscópico amostral }\end{array}$ & 3,5 & 0,0 & 0,0 \\
\hline & $\begin{array}{l}\text { Uso de critérios para escolher } \\
\text { áreas }\end{array}$ & 5,0 & 5,0 & 5,0 \\
\hline & $\begin{array}{l}\text { Planejamento de ações antes } \\
\text { de ir ao campo }\end{array}$ & 5,0 & 5,0 & 5,0 \\
\hline & $\begin{array}{l}\text { Cumprimento do intervalo de } \\
\text { dois anos }\end{array}$ & 5,0 & 0,0 & 0,0 \\
\hline & $\begin{array}{l}\text { Cobertura de áreas rurais e } \\
\text { urbanas }\end{array}$ & 5,0 & 2,5 & 5,0 \\
\hline \multirow{6}{*}{$\begin{array}{l}\text { Inquéritos } \\
\text { coproscópicos } \\
\text { censitários }\end{array}$} & $\begin{array}{l}\text { Uso de mecanismos para } \\
\text { diminuir a perda de potes }\end{array}$ & 5,0 & 5,0 & 5,0 \\
\hline & $\begin{array}{l}\text { Cumprimento da meta propos- } \\
\text { ta pela SES }\end{array}$ & 5,0 & 5,0 & 5,0 \\
\hline & $\begin{array}{l}\text { Cobertura de } 80 \% \text { da popu- } \\
\text { lação rural no período traba- } \\
\text { lhado }\end{array}$ & 5,0 & 5,0 & 5,0 \\
\hline & $\begin{array}{l}\text { Encaminhamento de pacientes } \\
\text { para o tratamento (ESF) }\end{array}$ & 5,0 & 5,0 & 2,5 \\
\hline & $\begin{array}{l}\text { Garantia de coproscopia de } \\
\text { controle }\end{array}$ & 5,0 & 2,5 & 5,0 \\
\hline & $\begin{array}{l}\text { Demarcação de estações de } \\
\text { captura }\end{array}$ & 3,5 & 0,0 & 0,0 \\
\hline \multirow[t]{2}{*}{$\begin{array}{l}\text { Controle do } \\
\text { molusco }\end{array}$} & $\begin{array}{l}\text { Realização de coleta periódica } \\
\text { de caramujos para identifi- } \\
\text { cação da taxa de infecção }\end{array}$ & 3,5 & 0,0 & 0,0 \\
\hline & $\begin{array}{l}\text { Realização de ações de controle } \\
\text { do molusco }\end{array}$ & 3,5 & 0,0 & 0,0 \\
\hline Saneamento & $\begin{array}{l}\text { Realização de ações de sanea- } \\
\text { mento }\end{array}$ & 3,5 & 0,0 & 0,0 \\
\hline \multirow[t]{2}{*}{$\begin{array}{l}\text { Educação em } \\
\text { saúde }\end{array}$} & $\begin{array}{l}\text { Realização de atividades educa- } \\
\text { tivas comprovadas em atas }\end{array}$ & 3,5 & 3,5 & 3,5 \\
\hline & $\begin{array}{l}\text { Existência de parcerias com } \\
\text { ONGs, associações de } \\
\text { moradores, etc. }\end{array}$ & 3,5 & 0,0 & 0,0 \\
\hline \multirow[t]{2}{*}{ SISPCE } & SISPCE implantado & 3,5 & 3,5 & 3,5 \\
\hline & $\begin{array}{l}\text { Digitação de casos provenientes } \\
\text { de demanda passiva no SISPCE }\end{array}$ & 3,5 & 0,0 & 3,5 \\
\hline \multirow[t]{2}{*}{$\begin{array}{l}\text { Vigilância epi- } \\
\text { demiológica }\end{array}$} & $\begin{array}{l}\text { Investigação de casos } \\
\text { graves/óbitos }\end{array}$ & 1,75 & 0,0 & 0,0 \\
\hline & $\begin{array}{l}\text { Digitação de casos graves no } \\
\text { SINAN }\end{array}$ & 1,75 & 1,7 & 1,7 \\
\hline \multirow[t]{4}{*}{$\begin{array}{l}\text { Indicadores de } \\
\text { cobertura* }\end{array}$} & $\begin{array}{l}\text { Percentual médio da população } \\
\text { trabalhada }\end{array}$ & 5,0 & 0,0 & 0,0 \\
\hline & $\begin{array}{l}\text { Percentual médio de amostras } \\
\text { recolhidas }\end{array}$ & 5,0 & 2,5 & 5,0 \\
\hline & Cobertura de tratamento & 5,0 & 2,5 & 5,0 \\
\hline & Periodicidade do fluxo & 5,0 & 5,0 & 5,0 \\
\hline Total de pontos & & 100,0 & 53,7 & 64,7 \\
\hline
\end{tabular}

*Para os indicadores de cobertura considerou-se a seguinte relação:

Percentual de: 80 a $100 \%=5$ pontos; de 50 a $79 \%=2,5$ pontos; de $49 \%$ ou menos = 0 ponto.

SES= Secretaria Estadual de Saúde; ESF= equipe de saúde da família; SISPCE= Sistema de informações sobre o programa de controle da esquistossomose; SINAN= sistema de informações sobre agravos de notificação; ONGs= organização não governamental. 
Calculou-se o GI do PCE para cada município, onde a pontuação alcançada pela estrutura (E) recebeu peso quatro e pelo processo $(\mathrm{P})$, peso seis. A fórmula para cálculo do GI foi: $\mathrm{GI}=\mathrm{E}(\mathrm{x} 4)+\mathrm{P}(\mathrm{x} 6)$ : 10. O GI do PCE foi classificado em três situações: implantado $=90$ a 100 pontos; parcialmente implantado $=60$ a 89 pontos e não implantado $<59$ pontos. O sistema de escores e os pontos de corte utilizados foram adaptados de Felisberto et al. 21 e Samico et al. 22

A análise do contexto utilizou o modelo político e contingente, proposto por Denis e Champagne, 15 que se inspira nas abordagens política e estrutural. A análise política buscou verificar a influência no grau de implantação do PCE considerando que os fatores ligados à implantação de uma intervenção dependem de interesses particulares dos atores influentes na organização. 15 Foram considerados como atores o secretário de saúde, coordenador do programa e o ASA que trabalha com o PCE, aos quais foram solicitados que informassem: a) se realizaram ações, dentro da sua governabilidade, que contribuíram para o controle da esquistossomose; b) se utilizam dados epidemiológicos para nortear as ações; c) se o planejamento ocorre de forma conjunta com PACS/PSF; d) se os atores participam da elaboração do Plano Municipal de Saúde (PMS); e) se consideram a esquistossomose como prioridade.

Por fim, a influência do contexto político no GI, segundo estes autores, pôde ser verificada a partir das respostas às seguintes interrogações: a) as relações entre os atores são modificadas pela implantação da intervenção?; b) em que as estratégias dos atores se opõem ou favorecem esta implantação? e; c) os atores que controlam as bases de poder na organização são favoráveis à implantação?

A abordagem estrutural preconiza que uma série de características referentes aos atributos organizacionais e aos dos gestores podem ter influência na determinação do GI de uma intervenção. $\mathrm{Na}$ análise dos atributos organizacionais foram levados em conta aqueles atributos que contribuem para a superação de estruturas rígidas que dificultam a adaptação às mudanças: 23 centralização, formalização do comportamento (controle da esquistossomose contemplado no PMS), cultura de planejamento, monitoramento e avaliação, especialização (grau de especialização dos atores), tamanho (se o município é integralmente responsável por garantir insumos e mão de obra). $\mathrm{Na}$ análise dos atributos dos gestionários, avaliou-se o perfil do coordenador, a atenção que o mesmo disponibiliza à inovação e se suas atitudes são limitadas. 15

O projeto foi aprovado pelo Comitê de Ética em
Pesquisas do Centro de Pesquisas Aggeu Magalhães / Fundação Oswaldo Cruz, conforme parecer $\mathrm{N}^{\circ}$ 013/2009.

\section{Resultados}

O grau de implantação (GI) do PCE no município 1 foi 52,85 (não implantado), e o GI do PCE no município 2 foi 63,65 (parcialmente implantado). A dimensão 'Processo' apresentou um melhor desempenho do que a 'Estrutura'.

A Tabela 1 mostra a distribuição da pontuação atingida por cada subcomponente da dimensão Estrutura e a pontuação total por esta dimensão. A maior carência entre os recursos materiais foi relacionada aos mapas e croquis, etiquetas marcadoras, Praziquantel ${ }^{\circledR}$, material de malacologia e espaço para o núcleo de educação em saúde. Com relação a recursos humanos e formação da equipe de trabalho, observou-se a inexistência de profissionais habilitados para exercer atividades de educação em saúde.

Os indicadores de cobertura de habilitação profissional mostraram que algumas categorias profissionais importantes para o controle da esquistossomose nunca receberam treinamento para suas funções, a exemplo daqueles que trabalham na atenção básica.

A Tabela 2 mostra a pontuação atingida por cada subcomponente e a pontuação total atingida para a dimensão processo. Apesar de ambos os municípios cumprirem a meta de exames proposta pela Secretaria Estadual de Saúde (SES), nenhum trabalha com delimitação epidemiológica da esquistossomose utilizando inquéritos amostrais, não trabalham uma mesma localidade por dois anos consecutivos, não realizam ações de controle do molusco nem de saneamento, não possuem parcerias com órgãos de participação da comunidade, não investigam casos graves e óbitos por esquistossomose nem trabalham o percentual mínimo da população de uma localidade ( $80 \%$ é o recomendado pelo MS).

Os indicadores de cobertura evidenciaram que o percentual médio da população trabalhada por ano é muito baixo (4,7\% para o município 1 e $6,7 \%$ para o município 2) em ambos os municípios, em comparação aos $80 \%$ recomendados pelo MS, o que lhes conferiu pontuação zero. O município 1 recolheu $76 \%$ dos coletores para material fecal e tratou $77,5 \%$ dos doentes, para o que pontuou 2,5 . O município 2 recolheu $86 \%$ dos potes e tratou $89 \%$ da população, recebendo pontuação completa. Ambos enviaram dados anualmente para a SES/PE e receberam 5 pontos. 
A Tabela 3 mostra o resultado da associação entre os aspectos considerados na análise do contexto político e o GI do PCE. Note-se que o ator secretário de saúde foi omitido, devido ao fato de que, em um dos municípios, este ator se reservou o direito de não participar da entrevista, e por isso, a influência do contexto político sob a perspectiva desse ator não pôde ser verificada. Apesar disto, foi possível aferir algumas características comuns aos dois municípios, com destaque para aquelas presentes nos ASA: ambos realizaram, dentro da sua governabilidade, ações que vieram a somar-se àquelas de rotina de controle da esquistossomose, contribuindo positivamente (POS) para o seu controle, porém, não apresentaram conhecimento satisfatório sobre o funcionamento do PCE, nem sobre os indicadores por ele gerados, como também não realizam planejamento de qualquer natureza nem consideram a esquistossomose como prioridade no município. Todos estes fatores influenciaram negativamente (NEG) a implantação do PCE em ambos os municípios.

Com relação aos coordenadores, constatou-se a presença de mais características positivas no coordenador do município 2 do que no do município 1 . Apesar de ambos terem realizado ações que beneficiaram o controle da esquistossomose na instância local e de evidenciarem conhecimento satisfatório sobre o funcionamento do PCE, somente o coordenador do município 2 conhecia os indicadores básicos do programa e considerava a esquistossomose como prioridade. Estes resultados mostram que existe um contexto mais favorável à implantação do PCE no município 2, que pareceu contribuir para que o GI do PCE se apresentasse melhor implantado nesse município.

A Tabela 4 mostra a associação observada entre os atributos organizacionais e dos gestionários e o GI do PCE. Verifica-se que, considerando os atributos dos gestionários, os municípios não apresentaram analogias: o coordenador do município 1 apresentava um perfil profissional favorável à implantação do PCE, porém, esse perfil não foi acompanhado de ações correspondentes, como observado no coordenador do município 2, que mostrou interesse por adequar o número de exames à realidade local $\mathrm{e}$ trabalhar localidades novas, buscando conhecer o perfil da esquistossomose nestas áreas, além de já ter levado o assunto esquistossomose ao Conselho Municipal de Saúde (CMS).

Quanto aos atributos organizacionais, viu-se que, no município 2, os coordenadores têm mais autonomia para tomar decisões. Esta propriedade, somada àquelas observadas no coordenador, pare- ceram influenciar na diferença encontrada entre os GI dos dois municípios. Apesar de neste município o PCE encontrar-se parcialmente implantado $(63,65)$, este resultado foi melhor que o do município 1 , onde o PCE evidenciou-se não implantado. Os demais atributos organizacionais mostraram-se similares nos dois municípios. Merecem destaque algumas características importantes: em nenhum deles ocorre o planejamento e monitoramento adequado das ações de controle, além de não oferecerem a estrutura necessária nem adquirem os insumos com recursos próprios. Essas características, somadas a outras já citadas, contribuíram para que o PCE estivesse não implantado nos municípios.

\section{Discussão}

As principais dificuldades encontradas durante a realização do estudo foram os sucessivos deslocamentos para os municípios e a inexistência de um instrumento consolidado de avaliação do PCE. A principal facilidade foi a disponibilidade dos profissionais em participarem das entrevistas. A recusa na participação do secretário de saúde em um dos municípios não foi considerada como uma dificuldade, mas como um acontecimento normal, inerente a processos de pesquisa comprometidos com a ética. Importa observar, ainda, que tal ausência não prejudicou os objetivos do estudo.

Durante o processo de construção do modelo lógico, a identificação dos componentes e de suas relações explicitou como o programa idealmente deve funcionar, 24 além do que o seu detalhamento também tornou possível a definição dos indicadores e critérios de avaliação que permitiram a mensuração da adequação da estrutura e dos processos. 25 Isso possibilitou o confronto entre a implantação do PCE, observada na realidade empírica, e a teoria do programa, permitindo verificar a importância da construção deste modelo para estudos avaliativos e para os serviços de saúde em geral.

Considerando-se esta proposição, pôde-se constatar a existência de discordância entre o que está proposto nas normas, no tocante à estrutura e ao processo e a realidade empírica, o que resultou na não implantação do PCE nos dois municípios. Cabe destacar que a dimensão do processo apresentou melhor situação do que a dimensão da estrutura em ambos os municípios. Isso pode refletir o fato de que os atores, mesmo dispondo de recursos escassos, procuram usar da criatividade para realizar as ações que estão ao seu alcance. Por outro lado, esses resultados sofreram a influência do contexto não favorável observado, ponderando-se tanto a abor- 


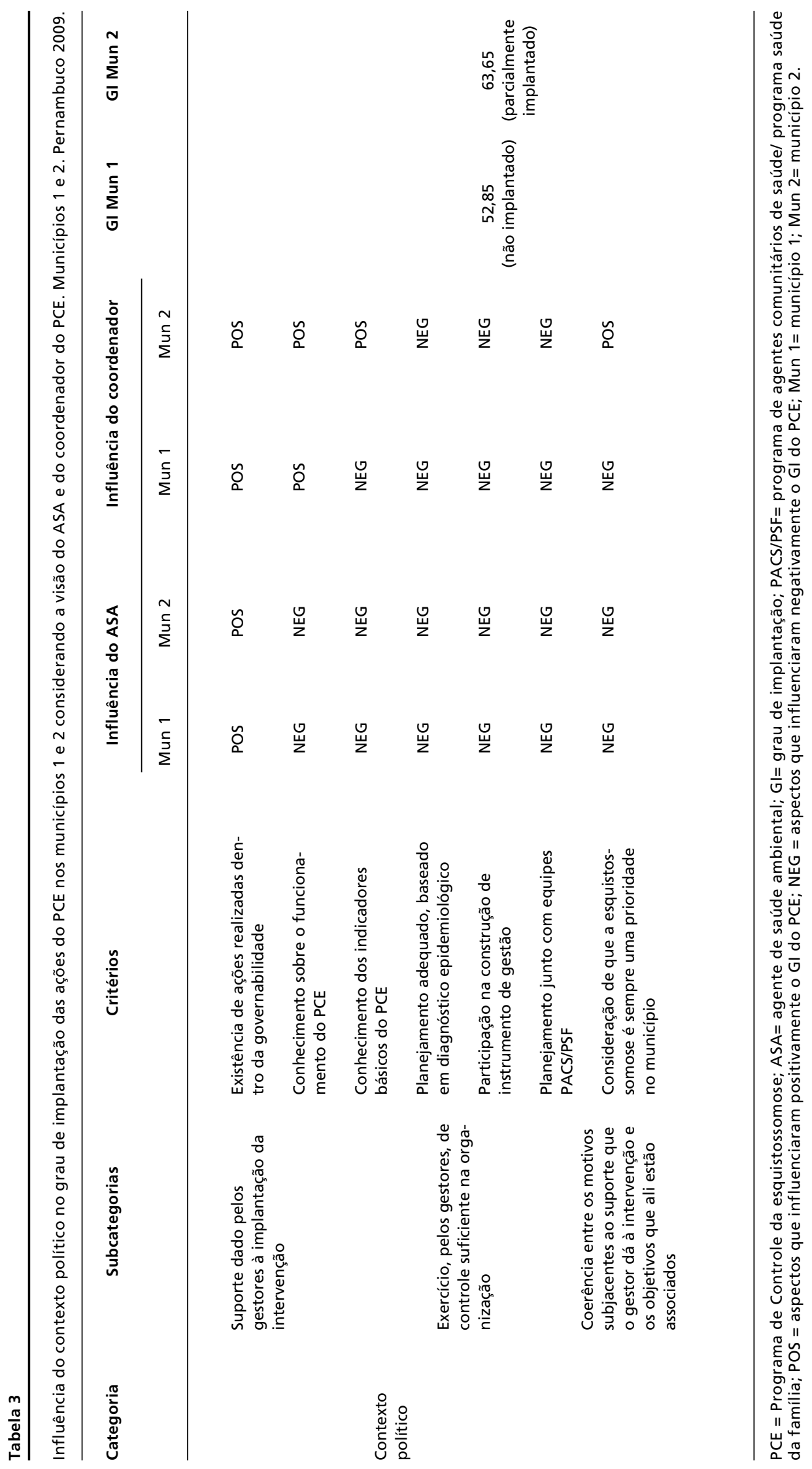




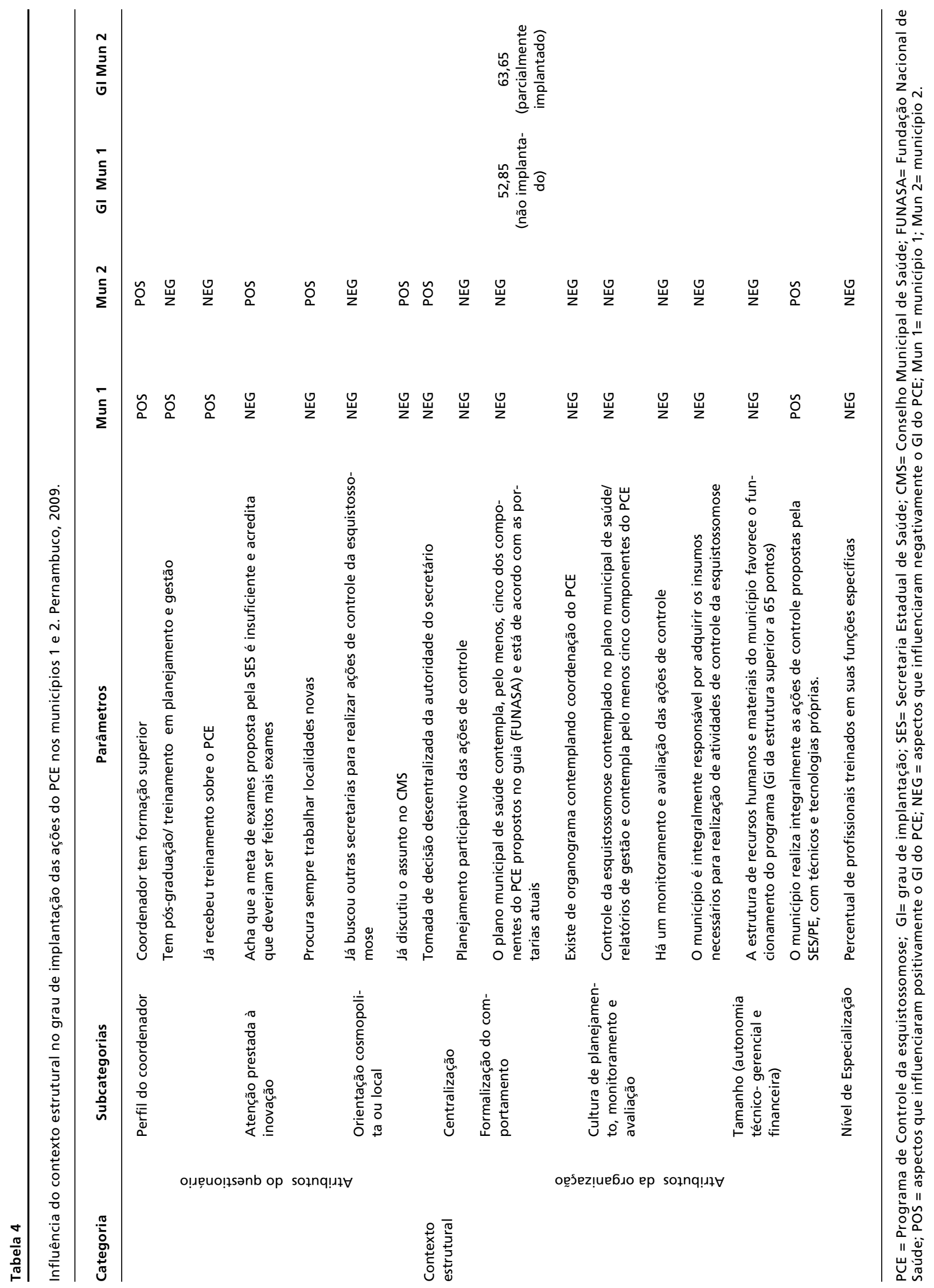


dagem política quanto a estrutural.

A análise segundo a abordagem política revelou que o conhecimento insuficiente a respeito do PCE, o planejamento precário das ações de controle e a pouca prioridade dada à esquistossomose contribuíram para explicar a não implantação do PCE. A vinculação do modo de realização das ações de controle da esquistossomose aos moldes da extinta SUCAM pode explicar estas condutas. Sabese que o controle das grandes endemias, segundo este órgão, era feito de forma vertical e visando a objetivos bem definidos, ${ }^{8}$ desconsiderando uma série de características regionais, 26 o que também evidencia a incipiência da descentralização das ações de controle desta endemia. Chama atenção o fato de as ações mínimas de planejamento não serem realizadas em conjunto com as equipes de PACS/PSF, favorecendo a dissociação entre as atividades de vigilância e assistência, em desacordo com a normatização atual.

Essa desagregação atenção/vigilância parece ser um ponto crucial nos serviços. Omotto et al., 27 analisando a implementação do Programa Nacional de Controle da Dengue (PNCD) no Paraná, verificaram que $5,6 \%$ dos ASA entrevistados relataram que uma das dificuldades de seu trabalho é a comunicação com o PACS/PSF. Chiaravalloti Neto 28 também detectou, no discurso dos ASA, em um trabalho que avaliou o PNCD em São Paulo, vários descompassos entre as atribuições e desempenho de tarefas, além da falta de reconhecimento do trabalho, disparidade entre os salários e diferenciação no treinamento. Outra pesquisa, realizada por Menezes, 29 avaliando o sistema de vigilância epidemiológica da esquistossomose na Bahia, também verificou a falta de entrosamento entre as equipes de vigilância e atenção.

Com o objetivo de verificar a influência do contexto político no GI do PCE, procederam-se às respostas às questões propostas por Denis e Champagne. ${ }^{15}$ Em relação à primeira questão, podese dizer que não foram observadas mudanças nas relações entre os atores, já que a implantação do PCE não mudou a maneira desagregada de planejar e executar as ações de controle, uma vez que esta atividade ainda ocorre sem a participação de equipes de PACS/PSF e os atores não participam da elaboração do PMS. Em atenção à segunda questão, podese dizer que, mesmo que os atores tenham realizado ações dentro da governabilidade, como por exemplo, reuniões periódicas dos coordenadores com os ASA tendo em vista a atualização de conhecimentos, assim como a utilização de estratégias por parte dos ASA para aumentar a adesão da comunidade ao programa, estas não foram suficientes no sentido de favorecer a implantação do PCE, já que outras estratégias podem ser apontadas como se opondo à implantação do PCE. Quanto à terceira questão, o fato de os atores mostrarem conhecimento insuficiente sobre o funcionamento e os indicadores do PCE e de não considerarem a esquistossomose como prioridade mostram uma atitude pouco partidária à implantação do PCE. Todos estes fatores implicam em um contexto não favorável à implantação do PCE em ambos os municípios. Estes resultados atendem, portanto, ao modelo proposto por Denis e Champanhe 15 e adotados neste estudo como referencial para análise de implantação, assim como se constituem em características contextuais que podem influenciar o GI segundo a abordagem política em que o modelo citado se fundamenta.

O modelo defendido por Denis e Champagne 15 também utiliza a abordagem estrutural para determinar a influência do contexto no GI. Segundo esses autores, essa influência pode ser medida através da resposta à seguinte indagação: as características dos gestionários e da organização favorecem a implantação da intervenção?

O presente estudo revela não haver associação direta entre as variáveis escolhidas para análise do contexto estrutural considerando os atributos dos gestionários e os GI encontrados, o que pode ser explicado por uma possível insuficiência de sensibilidade dessas variáveis em influenciar a diferença nos GI, encontrada nos municípios.

Já a análise dos atributos organizacionais mostrou que a falta de planejamento, monitoramento e avaliação das ações de controle, evidenciada, neste caso, pela não contemplação dos componentes do PCE nos instrumentos de gestão, assim como a concentração das ações de controle no âmbito da secretaria de saúde, e a estrutura física insuficiente foram os fatores organizacionais que contribuíram para explicar a não implantação do PCE nesse estudo. Pôde-se verificar, portanto, que as características observadas na organização não foram favoráveis à implantação do PCE.

Os resultados do estudo mostram ainda que, embora tenha ocorrido a municipalização das ações de controle da esquistossomose, passos importantes ainda precisam ser dados no que diz respeito à descentralização destas ações, a fim de que se possa superar a metodologia de trabalho utilizada pela extinta SUCAM e, assim, alcançar o esperado controle dessa endemia, particularmente no Estado de Pernambuco. 


\section{Referências}

1. Barbosa CS, Silva CB, Barbosa FS. Esquistossomose: reprodução e expansão da endemia no Estado de Pernambuco no Brasil. Rev Saúde Pública. 1996; 30: 60916.

2. Barbosa CS, SILVA CB. Epidemiologia da esquistossomose mansônica no engenho Bela Rosa, município de São Lourenço da Mata, PE. Cad Saúde Pública. 1992; 8: 83-7.

3. Barbosa CS, Favre TC, Wanderley TN, Callou AN, Pieri OS. Assessment of schistosomiasis through scholl surveys in the forest zone of Pernambuco, Brazil. Mem Inst Oswaldo Cruz. 2006; 101: 55-62.

4. Gonçalves J, Coutinho A, Santana W, Barbosa CS Esquistossomose aguda, de caráter episódico, na Ilha de Itamaracá, Estado de Pernambuco. Cad Saúde Pública. 1991; 7: 424-5.

5. Barbosa CS, Araujo K, Favre TC, Pieri OS. Spatial distribution of schistosomiasis foci on Itamaracá Island, Pernambuco, Brazil. Mem Inst Oswaldo Cruz. 2004; 99 : 79-83.

6. Barbosa CS, Pieri OS, Barbosa FS. Ecoepidemiologia da esquistossomose urbana na ilha de Itamaracá, Estado de Pernambuco. Rev Saúde Pública. 2000; 34: 337-41.

7. Barbosa CS, Domingues ALC, Abath F, Montenegro SML, Guida U, Carneiro J. Epidemia de esquistossomose aguda na praia de Porto de Galinhas, Pernambuco, Brasil. Cad Saúde Pública. 2001; 17: 725-8.

8. Teixeira MGLC, Paim JS. Os programas especiais e o novo modelo assistencial. Cad Saúde Pública. 1990; 6: 264-77.

9. Favre TC, Pieri OS, Barbosa CS, Beck L. Avaliação das ações de controle da esquistossomose implementadas entre 1977 e 1996 na área endêmica de Pernambuco, Brasil. Rev Soc Bras Med Trop. 2001; 34: 569-76.

10. Brasil. Congresso Nacional. Portaria ${ }^{0} 1399$. [acesso em: 12 dez 2008]. Disponível em: http://www.rebidia.org.br/ noticias/saude/port1399.html.

11. Brasil. Portaria $n^{\circ} 1172$ de 15 de junho de 2004. [acesso em 26 ago 2009a]. Disponível em: http://dtr2001.saude. gov.br/sas/PORTARIAS/Port2004/GM/GM-1172.htm.

12. Brasil. Ministério da Saúde. Secretaria de atenção à Saúde. Departamento de atenção à saúde. Cadernos de atenção básica n ${ }^{\circ}$ 21- Vigilância em saúde: Dengue, Esquistossomose, Hanseníase, Malária, Tracoma e Tuberculose. Brasília, DF; 2008.

13. Farias LMM, Resendes APC, Sabroza PC, Souza-Santos R. Análise Preliminar do sistema de informação do programa de controle da esquistossomose no período de 1999 a 2003. Cad Saúde Pública. 2007; 23: 235-9.

14. Quinino LRM, Aguiar LR, Costa JMBS, Barbosa, CS Avaliação das atividades de rotina do programa de controle da esquistossomose em municípios da região metropolitana do Recife, Pernambuco, entre 2003 e 2005. Epidemiol Serv Saúde. 2009; 18: 335-43.

15. Denis J, Champanhe F. Análise da implantação. In: Hartz Z. Avaliação em saúde: dos modelos conceituais à prática na análise da implantação de programas. Rio de Janeiro:
Fiocruz; 1997. p. 49-88.

16. McLaughlin JA, Jordan GB. Logic models: a tool for telling your program's performance story. Eval Program Plann. 1999; 22: 65-72.

17. Brasil. Portaria $\mathrm{n}^{\circ} 64$ de 30 de maio de 2008. [acesso em 3 nov 2009]. Disponível em: http://bvsms.saude.gov.br/ bvs/saudelegis/svs/2008/prt0064_30_05_2008.html.

18. Brasil. Fundação Nacional de Saúde. Controle da esquistossomose - diretrizes técnicas. Brasília, DF; 1998.

19. Brasil. Portaria 3252 de 22 de dezembro de 2009. [acesso em 29 jan 2010]. Disponível em: http://portal.saude.gov.br/ portal/arquivos/pdf/portaria3252_da_vigilancia_em_saude 0501.pdf.

20. Quinino LRM, Samico IC, Barbosa CS. Análise da implantação do Programa de Controle da Esquistossomose em dois municípios da zona da mata de Pernambuco, Brasil. Cad Saúde Coletiva (Rio J.) 2010. (No prelo).

21. Felisberto E, Carvalho EF, Maggi RS, Samico I. Avaliação do processo de implantação da estratégia da atenção integrada às doenças prevalentes da infância no programa saúde da família, no Estado de Pernambuco, Brasil. Cad Saúde Pública. 2002; 18: 1737-45.

22. Samico I, Hartz ZMA, Felisberto E, Carvalho EF. Atenção à saúde da criança: uma análise do grau de implantação e da satisfação de profissionais e usuários em dois municípios do Estado de Pernambuco, Brasil. Rev Bras Saúde Matern Infant. 2005; 5: 229-40.

23. Pompermayer CB. A influência de fatores organizacionais no sistema de gestão de custos: um estudo de caso. [acesso em nov 2008]. Disponível em: http://www.fae.edu/intelligentia/noticias/lerNoticia.asp?lngIdNoticia $=6134$

24. Medina MG, Silva GAP, Aquino R, Hartz ZMA. Uso de modelos teóricos na avaliação em saúde: aspectos conceituais e operacionais. In: Hartz ZMA, org. Avaliação em saúde: dos modelos teóricos à prática na análise da implantação de programas. Rio de Janeiro: Fiocruz; 2005. p. 41-63.

25. Donabedian A. The seven pillars of quality. Arch Pathol Lab Med. 1990; 114: 1115-8.

26. Carvalho EMF, Acioli MD, Costa AM, Cesse EAP, Branco MAF, Andrade AG, Mello EML. A expansão e o desafio de controlar a endemia esquistossomótica em Pernambuco: centralização e verticalidade das ações. An Fac Med Univ Fed Pernamb. 1998; 43: 155-61.

27. Omotto CA, Santini SML, Esteves JLM. Controle da dengue: uma análise da implementação do PNCD e a relação do processo de trabalho na $16^{\mathrm{a}} \mathrm{RSA}$. Apucarana/ Paraná - Brasil. Revista do II Congresso CONSAD de Gestão Pública. Porto Alegre, RS; 2008. p 69-70.

28. Chiaravalloti Neto A. O programa de controle do dengue em São José do Rio Preto, São Paulo, Brasil: dificuldades para a atuação dos agentes e adesão da população. Cad Saúde Pública. 2007; 23: 1656-64. 
29. Menezes MJR. Avaliação do sistema de vigilância epidemiológica da esquistossomose no Estado da Bahia [dissertação]. Rio de Janeiro: Escola Nacional de Saúde Pública da Fundação Oswaldo Cruz; 2005.

Recebido em 30 de abril de 2010

Versão final apresentada em 29 de julho de 2010

Aprovado em 28 de setembro de 2010 